\title{
US army survey targets Gulf War syndrome
}

Jonathan Knight, San Francisco

In a push to avoid trouble with mysterious post-conflict syndromes, the Pentagon is stepping up efforts to monitor the health of soldiers before and after their deployment in the Middle East.

Some scientists who have studied 'Gulf War syndrome' - the set of maladies associated with active service in the last Gulf War - applaud the effort. But others doubt whether it will pinpoint the source of health problems, should they occur during any conflict in Iraq.

The effort relies mainly on questionnaires. One, which all soldiers must now fill in before they are deployed and again when they return, asks about the soldier's general health and whether he or she is concerned about "possible exposures" during deployment. Responses are stored in a computer database maintained under a project called the Army Medical Surveillance Activity.

A more extensive questionnaire is being given to participants in the Millennium Cohort, a 21-year health study of some 100,000 service members that began in 1999 . The survey, given every three years, tracks

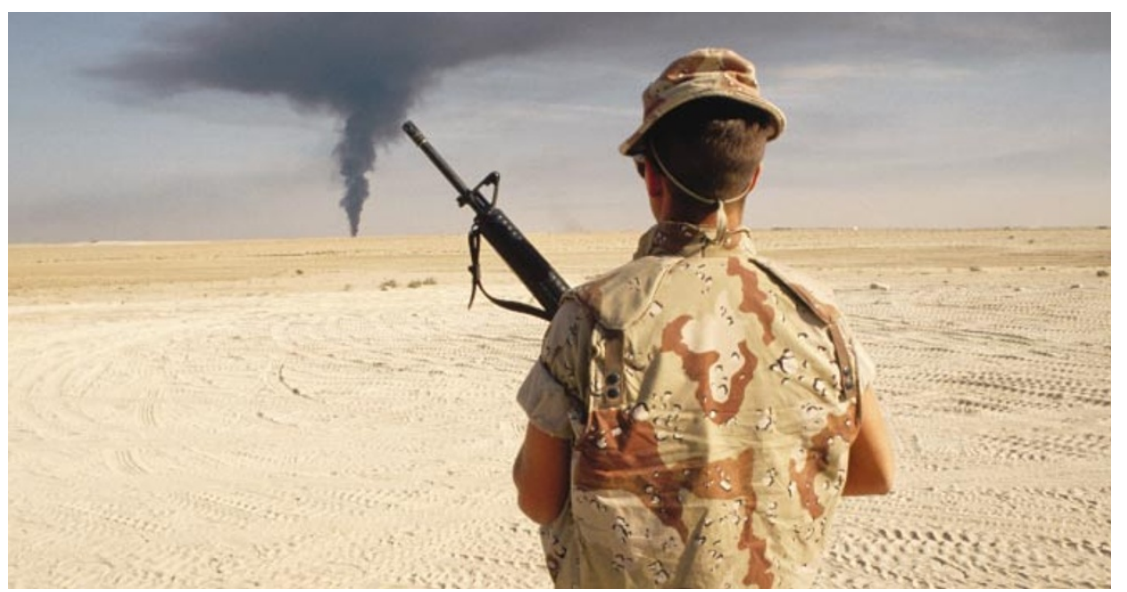

The US army is keen to use experience of the Gulf War to monitor health problems in any Iraq conflict.

the participants' health with questions about sleeplessness, stress symptoms, fitness, and alcohol and tobacco use. It also allows subjects to report their own health concerns.

If a group of veterans with related health problems crops up in either survey, military researchers will use records of troop movements to spot any locations or health hazards

\section{TB medic wins global health post}

\section{Declan Butler, Paris}

Jong Wook Lee, a South Korean physician, is set to succeed Gro Harlem Brundtland as director-general of the World Health Organization (WHO).

Lee, who has worked for the agency for 19 years, emerged victorious after a secret ballot by the agency's 32-member executive board on 28 January. It was a close finish with Peter Piot, a former AIDS researcher who now heads the Joint UN Programme on HIV/AIDS (UNAIDS). Both men were neckand-neck after the second round of voting, with Lee clinching the win in a tiebreaker vote. Pascoal Mocumbi, Mozambique's prime minister, who had been tipped as a favourite for the post (see Nature 421, 302; 2003), was eliminated in the first round.

Lee has served as head of the WHO's vaccine and immunization programme, and since $\mathbf{2 0 0 0}$ has fronted the agency's Stop TB programme. This widely commended initiative involves a consortium of 250 partners including WHO member states, donors, industry and non-governmental organizations.

In his election manifesto, Lee said that targeted investment in particular diseases was not sufficient to make a dent in the global health burden. He promised to press for "substantial investments in health services".

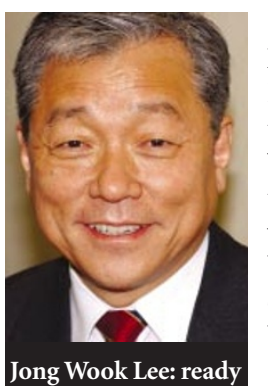

Lee also said that he would continue Brundtland's efforts to restructure the WHO, which at the time she took over was widely criticized for being an ineffective, excessively politicized bureaucracy.

Brundtland to head the World Health Organization. succeeded in putting the WHO and global health issues such as malaria and TB on the international agenda. But she was less successful in her reforms to streamline the agency, and many staff complain of an aloof management culture.

Lee has pledged to boost the low morale among WHO staff, and launch employment programmes to attract the best recruits. He also plans to decentralize the management of WHO programmes to relevant regions, for example by shifting the leprosy programme to India, and traditional medicine to its western Pacific regional office.

The nomination must now be approved by the WHO's 192 member states at the 56th World Health Assembly in Geneva in May, with the new director-general beginning his five-year term on 21 July. that they might have had in common.

That will be easier today than it was ten years ago, says John Resta, director of health risk management at the US Army Center for Health Promotion and Preventive Medicine in Maryland. Since the Gulf War, the army has stepped up water- and air-quality monitoring, he says, and it now deploys special teams to assess unusual hazards such as radiation and chemical contamination. These tests are linked to daily troop movements in a central database.

But even with all these data, the cause of something akin to Gulf War syndrome would be very hard to track, says Robert Sapolsky, a stress biologist at Stanford University. Too many disparate factors seem to contribute. For example, recent evidence suggests that stress can open the blood-brain barrier, rendering relatively harmless levels of contaminants more dangerous.

Epidemiologist Robert Haley at the University of Texas Southwestern Medical Center in Dallas, who believes some Gulf War veterans suffered brain damage from exposure to nerve gas, says that the surveys may mask such problems. Any brain injuries would almost certainly show up as stress problems in such broadly targeted questionnaires. "They will just say there is lots of posttraumatic stress disorder," he says.

But Simon Wessely, an epidemiologist at King's College London who has led the British effort to understand Gulf War health issues, supports the army's plan to look at a wide array of health issues. Wars invariably produce post-war syndromes, but the symptoms are always different, he says. After the Boer War, many soldiers complained of rheumatism, whereas stomach problems and fatigue prevailed after the Second World War (E. Jones et al. Br. Med. J. 324, 321-324; 2002). So it makes sense to cast a wider net. "You can't say what the injuries will be, only that there will be injuries," Wessely says. 